\title{
ENANTIOSELECTIVE DEPROTECTION OF N-PROTECTED AMINO ACIDS BY D-AMINOACYLASE
}

\author{
Hao-Ping Chen ${ }^{a}$, Shih-Hsiung $W^{*}{ }^{*}$ ac Ying-Chieh Tsai ${ }^{b}$, Yunn-Bor Yang ${ }^{b}$ \\ and Kung-Tsung Wangac \\ aGraduate Institute of Biochemical Sciences, \\ National Taiwan University \\ bInstitute of Biochemistry, National Yang-Ming Medical College \\ and \\ Institute of Biological Chemistry, Academia Sinica \\ P.O.Box. 23-106, Taipei, Taiwan, ROC \\ (Received 15 April 1992)
}
Summary : D-Aminoacylase isolated from Alcaligenes faecalis DA1 could enantioselectively deprotect racemic $\mathrm{N}$-protected [such as benzoyl (Bz-) and benzyloxycarbonyl ( $\mathrm{Z}-$-) groups] amino acids to produce free $D$-amino acids. The active site of the enzyme are roughly described.

D-Aminoacylase had been isolated and purified from Alcaligenes faecalis $^{1}$. According to the previous reports, the enzyme could catalyzes the hydrolysis of various $\mathrm{N}$-acetyl (Ac)-D-amino acids to free $\mathrm{D}$-amino acids. In order to study the substrate specificity of the enzyme and to gain a better understanding of its active site, various $\mathrm{N}$-protected amino acids are used as substrates and the results are listed in Table 1. The topography of the active site of the enzyme is proposed to possess uniquely oriented binding loci that are complementary to each of the four groups attached to the $\alpha$-carbon of the amino acids derivatives (Scheme 1). The $\mathrm{N}$-acyl group of amino acid substrates play an important role in the specificity of the enzyme. The $n$-site is the catalytic site, since the hydrolysis will not take place unless 
the susceptible group is bound. Judging from the hydrolytic rate, the order for optimal binding of $n$-site is acetyl $>\mathrm{Bz}>\mathrm{Z}$; Boc- $(t$ butyloxycarbonyl) and $n$-octyl groups are not allowed to be accepted probably due to the steric hindrance. The $h$-site doesn't contribute directly to binding of a substrate and only small groups such as $\mathrm{H}$ can fit in this region. Because the substrates of the enzyme are restricted for Cterminal-free $(\mathrm{COOH})$ amino acid derivatives, the inside of $c$-site may have positive charge to form a salt bridge with the carboxyl group of the substrate. Not all $\mathrm{N}$-acetyl amino acids can be hydrolyzed and different amino acids show significantly different hydrolytic rates. This results indicated that the side chains $(R)$ of amino acids also play an important role in the enzymatic reaction. Obviously the $r$-site favors to

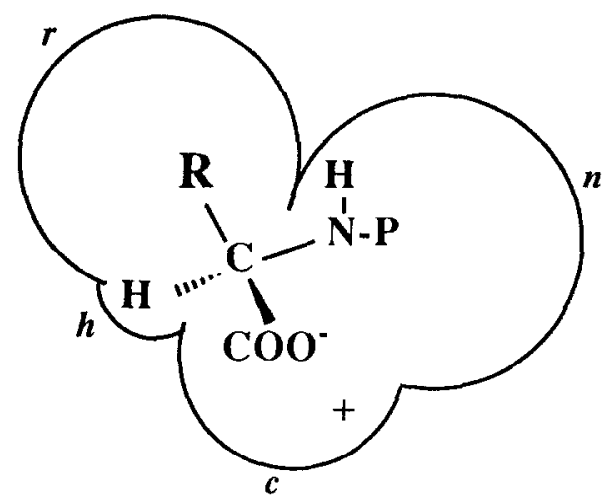

Scheme 1. The proposed active site of D-aminoacylase from Alcaligenes faecalis $P: N$-protected group

$\mathrm{R}$ : side chain of amino acids

bind hydrophobic side chain, then interacts with the $n$-site to trigger the hydrolytic activity. Based on the previous reports ${ }^{3}$ and the results shown in Table 1, several conclusions deserve to be mentioned: (i) the polar and charged side chain of amino acids such as Ser, Thr, Glu, Asp, 
Table 1. Enantioselective deprotection of N-protected DL-amino acids by D-aminoacylase from Alcaligenes faecalis ${ }^{a}$

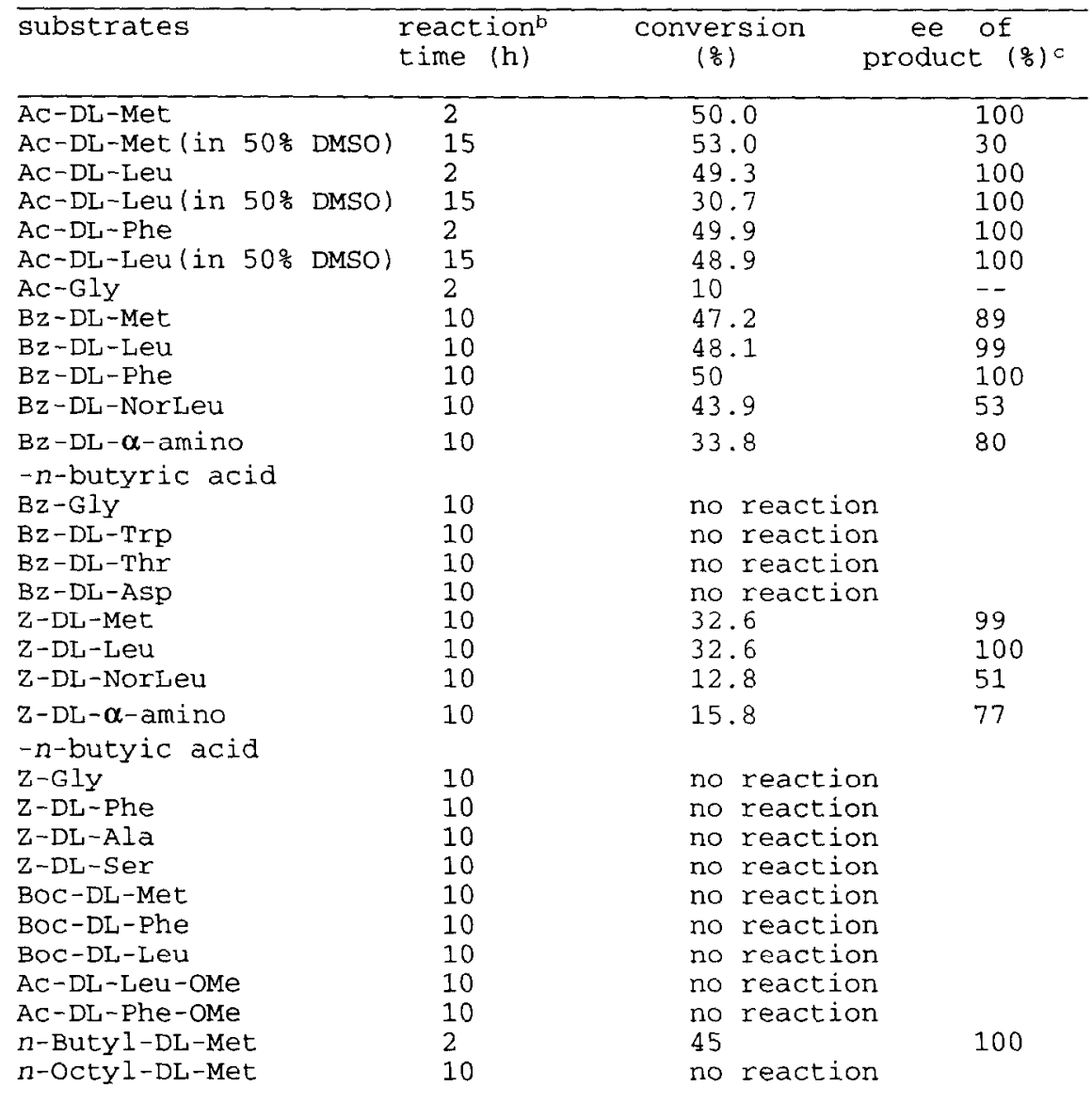

aThe enzyme was isolated and purified based on the previous paper ${ }^{1}$.

bo a solution of $20 \mathrm{mM}$ of the substrate in $0.6 \mathrm{~mL}$ of Tris buffer ( $\mathrm{pH} 7.8,0.05 \mathrm{M})$ was added $1 \mu \mathrm{gg}$ of the purified enzymes and incubated at $37^{\circ} \mathrm{C}$. The reaction progress (conversion) was determined by the concentration of free amino acids with ninhydrin test ${ }^{2}$.

cThe reaction was stopped by freezing with liquid nitrogen, lyophilized and then fractionated by HPLC $\mathrm{C}_{18}$ column with $\mathrm{CH}_{3} \mathrm{CN}$ $: \mathrm{H}_{2} \mathrm{O}: \mathrm{H}_{3} \mathrm{PO}_{3}=22: 78: 1$ as eluent. The fraction of free amino acid was collected and its ee (enantiomeric excess) was measured by $\mathrm{CR}(+)$ chiral column (Daicel Chemical Industries, LTD; Japan). 
Lys and Arg cannot be accommodated in the $r$-site and their $\mathrm{N}$ protected derivatives are not the substrates of the enzyme. (ii) the side chains of Gly and Ala are too small to have a productive binding with both $n$ - and $r$-sites. (iii) Bz-DL-Phe can be enantioselectively hydrolysed, but Z-DL-Phe can not be hydrolyzed. This result indicates that Bz-D-Phe just fits into the active site of the enzyme, but Z-D-Phe can not fit in, even though the latter is only slightly bulkier than the former. The enzyme still has hydrolytic activity in 50\% DMSO-aquaous solution, but the reaction rate and enantioselectivity are lower.

D-Aminoacylase had been isolated from several microorganisms ${ }^{4-}$ 7. After comparison, the enzyme described here showed higher enantioselectivity and activity. Like the preparation of L-amino acid derivatives by L-aminoacylases 8 , the enzyme appears to be useful for the preparaation of some $\mathrm{D}$-amino acid derivatives.

\section{References :}

1. Yang, Y. B., Lin, C. S., Tseng, C. P., Wang, Y. J. and Tsai, Y. C. Appl. and Environ. Microbiol., 1991, 57, 1259.

2. Rosen, H. Arch. Biochem. Biophy., 1957, 67, 10.

3. Yang. Y. B., Ph. D. dissertation (1991), Institute of Biochemistry, National Yang-Ming Medical College

4. Kameda, Y., Toyoura, E. and Kimura, Y., Nature, 1958, 181, 1225.

5. Kubo, K., Ishikura, T and Fukagawa, Y. J. Antibiot, 1980, 33, 550.

6. Tsai, Y. C., Tseng, C. P., Hsiao, K. M. and Chen, L. Y. Appl. and Environ. Microbiol., 1988, 54, 984.

7. Sakai, K., Obata, T., Ideta, K. and Moriguchi, M. J. Fermemt. Bioeng, $1991,71,78$.

8. Chenault, H. K., Dahmer, J., and Whitesides, G. M. J. Am. Chem. Soc., $1989,111,6354$. 